\title{
PROFUNDIDADE DE AMOSTRAGEM DO SOLO SOB PLANTIO DIRETO PARA AVALIACÃO DE CARACTERÍSTICAS QUÍMICAS ${ }^{(\mathbf{1})}$
}

\author{
P. M. SILVEIRA ${ }^{(2)} \&$ L. F. STONE ${ }^{(2)}$
}

\begin{abstract}
RESUMO
O trabalho foi realizado na Embrapa-CNPAF, em Santo Antônio de Goiás (GO), em Latossolo Vermelho perférrico textura argilosa, submetido a três sistemas de preparo, durante seis anos consecutivos (1992-1998), e cultivado com mi lho no verão e feijão no inverno, sob irrigação por pivô central. $\mathbf{O}$ objetivo foi determinar, para diferentes características químicas do solo, a profundidade de amostragem no sistema plantio direto que apresenta valores correspondentes aos obtidos na profundidade de amostragem recomendada para o solo preparado com arado (sistema convencional) e com grade aradora. As amostras foram coletadas com 40 repetições em cada sistema de preparo: nas profundidades de 0-10, 0-20, 5-20 e 10-20 cm no solo sob plantio direto, 0-20 cm sob preparo com arado de aiveca e 0-15 cm sob grade aradora. Empregou-se o delineamento inteiramente casualizado, com seis tratamentos, e as médias comparadas pelo teste de Tukey. Os valores de $\mathrm{P}$ e de $\mathrm{K}$ apresentaram as maiores variabilidades e os de pH, as menores. Para pH, Ca, Mg e K, a amostragem na profundidade de 0-10 cm de solo no plantio direto apresentou valores semel hantes aos obtidos na profundidade de $0-20 \mathrm{~cm}$ no sistema convencional com arado. Para o $P$, a profundidade de amostragem no plantio direto que teve o mesmo valor de disponibilidade do elemento no sistema convencional foi a de $10-20 \mathrm{~cm}$.
\end{abstract}

Termos de indexação: análise de solo, preparo do solo, solo de cerrado.

(1) Recebido para publicação em abril de 2000 e aprovado em setembro de 2001

(2) Engenheiro-Agronômo da Embrapa-CNPAF. Caixa Postal 179, CEP 75375-000 Santo Antônio de Goiás (GO). Bolsista do CNPq. E-mail: pmarques@cnpaf.embrapa.br 


\title{
SUMMARY: SOIL SAMPLING DEPTH UNDER NO-TILLAGE SYSTEM TO EVALUATE SOIL CHEMICAL CHARACTERISTICS
}

\begin{abstract}
This study was carried out at EMBRAPA-CNPAF, SantoAntônio deGoiás (GO), Brazil, in a clayey Oxisol, under three soil tillage systems, from 1992 to 1998. Corn was grown in the summer and common bean in the winter, under center pivot sprinkler irrigation. The objective was to comparethevalues of $\mathrm{pH}, \mathrm{Ca}, \mathrm{Mg}, \mathrm{P}$, and $\mathrm{K}$ of thesoil, sampled at different depths under no-tillage to those from soil under mol dboard plough tillage (conventional) and harrow tillage. Forty replicates were collected at 0-10, 0-20,5-20, and 10-20 cm soil depth under no-tillage, $0-20 \mathrm{~cm}$ soil depth under moldboard plough tillage, and $0-15 \mathrm{~cm}$ soil depth under harrow tillage. The Tukey test was used to compare the means of the chemical characteristics. The values of $\mathrm{pH}, \mathrm{Ca}, \mathrm{Mg}$, and $\mathrm{K}$ varied according to the tillage system. TheP and $\mathrm{K}$ had thehighest variability while $\mathrm{pH}$ had thelowest. Sampling at 0$20 \mathrm{~cm}$ depth under moldboard plough tillage showed $\mathrm{pH}, \mathrm{Ca}, \mathrm{Mg}$, and $\mathrm{K}$ values similar to sampling at 0-10 cm depth under no-tillage. For $\mathrm{P}$, the correspondent sample depth under no-tillage was $10-20 \mathrm{~cm}$.
\end{abstract}

Index terms: soil analysis, soil tillage, cerrado soil.

\section{NTRODUÇÃO}

Muitas vezes, a amostragem do solo para avaliação da fertilidade, em áreas de plantio direto, tem sido feita de modo semel hante à de áreas com preparo convencional. As áreas sob plantio direto, em virtude do não-revolvimento do solo, adquirem características que, numa amostragem convencional, poderão trazer problemas para a interpretação e recomendação de fertilizantes e corretivos (Vieira, 1996). Souza (1992) relatou queinúmeros trabal hos têm mostrado que os sistemas de manejo conservacionistas criam, no solo, um ambiente diferente daquele encontrado no sistema convencional, resultante do efeito dos resíduos superficiais e da reduzida movimentação do solo. Como conseqüência, tem-se constatado acúmulo de fertilizantes na superfície do solo nos sistemas conservacionistas.

O mai or vol umedosistema radicular das culturas anuais eas mai ores alterações quími cas efísicas em solos cultivados em plantio convencional ocorrem na camada de $0-20 \mathrm{~cm}$ de profundidade. Por estas razões, recomenda-se o uso de fertilizantes e corretivos com base na inter pretação dos resultados analíticos determinados em amostras obtidas nessa camada (Comissão de Fertilidade do Sol o do Estado de Minas Gerais, 1989; Oliveira et al., 1996).

Em plantio direto, o sol o geral mente encontra-se coberto por uma camada de resíduos orgânicos. Esses resíduos precisam ser retirados no momento da amostragem. É provável que a profundidade de amostragem revele a maior diferença entre a amostragem do sol o sob plantio direto e sob preparo convencional. Considerando a concentração dos nutrientes próximos à superfície, há necessidade de subdivisão da profundidade costumeiramente adotada em preparo convencional (Vieira, 1996). Se a subdivisão não for realizada, corre-se o risco de obter, na análise, um valor médio da fertilidade da camada amostrada, sem, no entanto, detectar a existência de um gradiente de fertilidade.

Anghinoni \& Salet (1995) questionam a necessidade de definir um novo sistema de recomendação de adubação ecal agem para o sistema plantio di reto, em virtude das modificações ocorridas nas características que definem os índices de fertilidade do solo, quando comparados aos do sistema convencional. Segundo esses autores, um novo sistema de recomendação não se justifica e, para usar o mesmo sistema de recomendação no sol o sob plantio direto, uma das alternativas de ajuste consiste em determinar a profundidade de amostragem no sistema plantio direto que tenha o índice de disponibilidade de nutrientes similar ao do solo preparado pelo sistema convencional, tendo como suportea similari dade de resposta das culturas nos dois sistemas.

Outroaspecto importanterefere-seà variabilidade das características químicas de um solo, mesmo em uma área considerada uniforme. Para que a amostragem do solo sob plantio direto represente com exatidão a sua fertilidade, são necessários al guns cuidados especiais. No plantio direto, como o solo não é revolvido, os fertilizantes concentramse nas linhas de semeadura das culturas, causando variabilidade da fertilidade. A amostragem no sulco de semeadura pode levar a erros de recomendação de adubação. SegundoVieira (1996), para evitar esse risco, em áreas com concentração de adubos na zona dos sulcos, a mel hor época para fazer a amostragem éno final do cicl o ou imediatamente após a col heita, quando ainda é possível distinguir as linhas da cultura presente. Entretanto, esteprocedimento pode 
não ser eficientese forem consi deradas as adubações em sulcos realizadas nos cultivos anteriores. Assim, quanto mais heterogêneo for o solo, mai or deve ser o número de amostras coletadas, para atingir determinada precisão na avaliação de suas características.

Estetrabal ho teve como objetivo determinar, para diferentes características químicas do solo, a profundidade de amostragem no sistema plantio direto que apresenta valores correspondentes aos obtidos na profundidade de amostragem recomendada para o solo preparado com arado (sistema convencional) e com grade aradora.

\section{MATERIAL E MÉTODOS}

O trabalho foi realizado em um Latossolo Vermelho perférrico, com $425 \mathrm{~g} \mathrm{~kg}^{-1}$ de areia, $172 \mathrm{~g} \mathrm{~kg}^{-1}$ de silte e $403 \mathrm{~g} \mathrm{~kg}^{-1}$ de argila na camada de 0-20 cm, na Embrapa-CNPAF, em SantoAntônio de Goiás (GO). A área foi cultivada de 1992 a 1998 com mil ho no verão e feijão no inverno, sob irrigação por pivô central. Foram feitos os cultivos sob os sistemas de preparo do solo com arado de aiveca e com grade aradora e sob plantio direto. No preparo com arado, usou-se arado de três aivecas, incorporando os resíduos até à profundidade de $30 \mathrm{~cm}$, seguido degradagem com gradedestorroadora. No preparo com grade aradora, foi usada grade de 20 discos, incorporando os resíduos até $15 \mathrm{~cm}$ de profundidade. No plantio direto, utilizou-se plantadora apropriada, permanecendo na superfície do sol o todo o resíduo das culturas. A área de cada tratamento foi de aproximadamente $1.200 \mathrm{~m}^{2}$.

Anualmente, foram aplicados $800 \mathrm{~kg} \mathrm{ha}^{-1} \mathrm{de}$ adubo no sulco de semeadura, sendo $400 \mathrm{~kg} \mathrm{ha}^{-1}$ no plantio de milho e $400 \mathrm{~kg} \mathrm{ha}^{-1}$ no plantio do feijão. As fórmulas de adubo utilizadas foram 2-29-17, 4-30-16, 5-30-15 e 4-18-12, para milho, e 2-30-15, 4-30-16 e 5-30-15, para feijão, dependendo do ano. Em outubro de 1995, foram aplicadas $2,5 \mathrm{t} \mathrm{ha}^{-1}$ de calcário em toda a área experimental, incorporandoo até à profundidade de ação dos implementos ou permanecendo na superfície do sol o no plantio di reto.

A semeadura do feijão do cultivo de 1998 foi feita no dia 15 de junho com o cultivar Aporé, no espaçamento de 0,45 mentrelinhas e 16-17 sementes por metro. Além da adubação de plantio, aplicaramse $40 \mathrm{~kg} \mathrm{ha}^{-1}$ de $\mathrm{N}$ em cobertura. Os dados de rendimento de grãos de feijão nos diferentes sistemas de preparo do solo foram submetidos à análise de variância.

As amostras de solo foram coletadas no ano de 1998, após a colheita do feijão, com 40 repetições, nas profundidades de $0-10,0-20,5-20$ e $10-20 \mathrm{~cm}$ no plantio direto, $0-20 \mathrm{~cm}$ no tratamento com arado de aiveca e 0-15 cm no tratamento com grade aradora, considerando 10 amostras simples para formar uma composta, definindo, assim, seis tratamentos. As amostras foram analisadas para $\mathrm{pH}$ em água, teores de $\mathrm{Ca}, \mathrm{Mg}$ e $\mathrm{K}$ trocáveis e teor de P extraível, conforme método descrito em Embrapa (1997). As variáveis foram analisadas exploratoriamente para conhecer seus valores médios e sua variabilidade (C.V.). Constatada a homogeneidade de variância entre os tratamentos para quase a totalidade das variáveis, os dados foram submetidos à análise de variância, utilizando o delineamento inteiramente casualizado e as médias comparadas pelo teste de Tukey a $5 \%$.

\section{RESULTADOS E DISCUSSÃO}

Pela análise da variância dos rendimentos de grãos do feijoeiro no cultivo de 1998, constatou-se similaridade de resposta da cultura aos sistemas de preparo do solo com arado de aiveca (2.095 kg ha), grade aradora (2.252 $\mathrm{kg} \mathrm{ha}^{-1}$ ) e plantio direto $\left(2.082 \mathrm{~kg} \mathrm{ha}^{-1}\right)$. Essa similaridadeéimportante, pois, juntamente com a similaridade de valores das características químicas do solo, permite, segundo Anghinoni \& Salet (1995), o uso de tabelas de recomendação de adubação do sistema convencional de preparo do sol o para o sistema plantio direto.

No quadro 1, são apresentados os valores médiose os coeficientes de variação das variáveis de solo estudadas. $\mathrm{O} \mathrm{pH}$ do solo a $0-10 \mathrm{~cm}$ de profundidade no sistema plantio direto não diferiu significativamente dos val ores obtidos nos preparos de sol o com arado de ai veca $(0-20 \mathrm{~cm})$ e grade aradora $(0-15 \mathrm{~cm})$. Os val ores obtidos no plantio direto nas camadas de 0-20, 5-20 e 10-20 cm não diferiram significativamente entre si e foram inferiores aos de outros preparos.

Os coeficientes de variação para esta variável foram baixos em todos os tratamentos, variando de 2,7 a 6,5\% (Quadro 1). Os maiores coeficientes de variação ocorreram no plantio direto, em todas as profundidades amostradas, concordando com os dados relatados por Anghinoni \& Sal et (1995) eSalet et al. (1997). Com o não-revolvimento do solo, como ocorre no plantio direto, esperava-se maior variabilidade dos dados neste tratamento.

Prevedello (1987) encontrou para o pH um coeficiente de variação de aproximadamente $3 \%$, quando estudou a magnitude da variabilidade espacial de uma Terra Roxa Estruturada, cultivada com arroz de terras altas. Segundo Souza (1992), o sistema convencional, usando grade aradora, apresentou menor variabilidade horizontal evertical nos teores de matéria orgânica e de nutrientes na camada arada do solo do que a escarificação e o plantio direto. Dentreestes, a escarificação mostrouse mais variável, por movimentar apenas algumas faixas no solo. 
Quadro 1. Valores médios e coeficientes de variação (C.V.) dos dados de pH $\left(\mathrm{H}_{2} \mathrm{O}\right), \mathrm{Ca}, \mathrm{Mg}, \mathrm{P}$ e $\mathrm{K}$, em diferentes profundidades de amostragem do solo, nos sistemas de preparo arado de aiveca, grade aradora e plantio direto

\begin{tabular}{|c|c|c|c|c|c|c|}
\hline \multirow{2}{*}{ Tratamento } & & \multicolumn{5}{|c|}{ Variável(1) } \\
\hline & & \multirow[t]{2}{*}{$\mathbf{p H}$} & $\mathrm{Ca}$ & Mg & $\mathbf{P}$ & $\mathbf{K}$ \\
\hline & & & \multicolumn{2}{|c|}{$\mathrm{mmol}_{\mathrm{c}} \mathrm{dm}^{-3}$} & \multicolumn{2}{|c|}{$\mathrm{mg} \mathrm{dm}^{3}$} \\
\hline Arado & Média & $5,6 \mathrm{a}$ & $18,0 \mathrm{a}$ & $9,1 \mathrm{ab}$ & $9,4 \mathrm{c}$ & $113 a$ \\
\hline $0-20 \mathrm{~cm}$ & C.V. (\%) & 3,2 & 16,4 & 17,1 & 50,0 & 37,5 \\
\hline Grade & Média & $5,5 a$ & $17,0 \mathrm{a}$ & $8,1 \mathrm{bc}$ & $22,7 \mathrm{ab}$ & $131 \mathrm{a}$ \\
\hline $0-15 \mathrm{~cm}$ & C.V. (\%) & 2,7 & 17,4 & 20,5 & 26,4 & 29,7 \\
\hline Plantio direto & Média & 5,4 a & $18,0 \mathrm{a}$ & $9,6 a$ & $26,2 \mathrm{a}$ & $109 a$ \\
\hline $0-10 \mathrm{~cm}$ & C.V. (\%) & 6,5 & 35,5 & 33,3 & 81,6 & 43,2 \\
\hline Plantio direto & Média & $5,1 \mathrm{~b}$ & $14,0 \mathrm{~b}$ & $7,1 \mathrm{~cd}$ & $15,5 \mathrm{bc}$ & $67 \mathrm{~b}$ \\
\hline $0-20 \mathrm{~cm}$ & C.V. (\%) & 6,2 & 33,2 & 34,0 & 82,7 & 62,4 \\
\hline Plantio direto & Média & $5,1 \mathrm{~b}$ & $13,0 \mathrm{~b}$ & $6,6 d$ & $13,3 \mathrm{c}$ & $41 c$ \\
\hline $5-20 \mathrm{~cm}$ & C.V. (\%) & 6,1 & 29,5 & 29,6 & 76,1 & 49,8 \\
\hline Plantio direto & Média & $5,2 b$ & $13,0 \mathrm{~b}$ & $6,8 \mathrm{~cd}$ & $9,3 \mathrm{c}$ & $39 c$ \\
\hline $10-20 \mathrm{~cm}$ & C.V. (\%) & 4,9 & 31,7 & 28,0 & 69,4 & 41,7 \\
\hline
\end{tabular}

(1) Valores seguidos das mesmas letras, na vertical, não diferem entre si pelo teste de Tukey a 5\%.

Com relação ao Ca (Quadro 1), os valores dos diferentes tratamentos: plantio direto na camada de 0-10 cm, arado de aiveca $(0-20 \mathrm{~cm})$ e grade aradora $(0-15 \mathrm{~cm})$ foram superiores aos do plantio direto nas profundidades de 0-20, 5-20 e 10-20 cm, de forma semel hante ao constatado para os valores de pH, o que também justifica os valores daquela variável. A maior concentração de Ca na camada de $0-10 \mathrm{~cm}$, no plantio direto, é conseqüência da calagem feita no quarto ano de cultivo, sem a incorporação do corretivo, mostrando uma real concentração desse el emento na camada superficial do solo.

Em todas as profundidades amostradas no plantio direto, ocorreram os maiores coeficientes de variação para o Ca, superiores aos do pH, mostrando ter este el emento maior variabilidade no solo.

Os maiores valores de $\mathrm{Mg}$ ocorreram no plantio direto na camada de $0-10 \mathrm{~cm}$ e no tratamento com arado de aiveca. Em todas as profundidades amostradas no plantio direto, ocorreram os maiores coeficientes de variação, os quais foram de magnitude semel hante aos do Ca.

Houve diferença significativa nos teores de $\mathrm{P}$ do solo entre os tratamentos. Os maiores valores médios ocorreram no plantio direto $(0-10 \mathrm{~cm})$ e no tratamento com gradearadora. Os menores val ores encontrados no arado de aiveca foram atribuídos ao revolvimento mais profundo, trazendo solo de menor fertilidade das camadas mais profundas para a superfície, o que diminuiu o teor de P na camada estudada.

No plantio direto $(0-10 \mathrm{~cm})$, percebeu-se uma concentração do el emento nessa camada, graças ao não-revolvimento do terreno e à baixa mobilidade do elemento no solo. U ma acumulação superficial de fósforo no plantio direto, em dois sol os, Latossolo Roxo distrófico e Latossolo Vermelho-Escuro distrófico argil oso, sobretudo nos primeiros $5 \mathrm{~cm}$ de profundidade, foi encontrada por Muzilli (1983). Segundo o autor, o maior acúmulo de fósforo nas camadas superficiais do solo sob plantio direto é explicado pela imobilidade e baixa solubilidade de seus compostos, sobretudo em solos de natureza ácida e com al tos teores de argila.

Os valores de $\mathrm{P}$ das amostragens das camadas de solo de 0-20, 5-20 e 10-20 cm de profundidade no plantio direto não diferiram significativamente do tratamento arado de aiveca e apresentaram alta variabilidade, refletida pelo alto coeficiente de variação. $O$ val or médio de $P$ do plantio direto mais próximo do tratamento arado de aiveca $\left(9,4 \mathrm{mg} \mathrm{dm}^{-3}\right)$ foi determinado na camada de $10-20 \mathrm{~cm}\left(9,3 \mathrm{mg} \mathrm{dm}^{-3}\right)$. Altos coeficientes de variação para $P$ também foram relatados por Muzilli (1983) e Salet et al. (1997). 
Houve efeito significativo dos sistemas de preparo sobre os teores de K no solo (Quadro 1). O val or de $\mathrm{K}$ do solo na camada de $0-10 \mathrm{~cm}$ de profundidade no plantio direto não diferiu significativamentedo val or obtido nos tratamentos com arado de aiveca (0$20 \mathrm{~cm}$ ) e grade aradora $(0-15 \mathrm{~cm})$. Os valores obtidos no plantio direto nas demais camadas foram estatisticamente iguais e inferiores aos demais. Os coeficientes de variação também foram altos para esta variável, porém um pouco inferiores aos encontrados para o $\mathrm{P}$.

Segundo Salet et al. (1997), a alta variabilidade do fósforo no solo está relacionada com as linhas de adubação. A variabilidade do potássio no solo está relacionada não só com as linhas de adubação, mas também com a localização das plantas, pois este el emento não forma compostos orgânicos no tecido das plantas, sendo facilmentetransportado da parte aérea para o solo após a chuva. Destemodo, tendea concentrar-se na proximidade do colo da planta e diminuir com o afastamento da mesma.

Analisando o quadro 1 , verifica-se que a profundidade de amostragem do solo no sistema plantio direto, que apresentou o mesmo índice de disponibilidade de $\mathrm{Ca}, \mathrm{Mg}, \mathrm{K}$ e valor de $\mathrm{pH}$ ao do sistema convencional (arado), foi a de $0-10 \mathrm{~cm}$. Para o P, o val or encontrado na profundidade de $0-10 \mathrm{~cm}$ do plantio direto $\left(26,2 \mathrm{mg} \mathrm{dm}^{-3}\right)$ diferiu muito do valor do tratamento com arado $\left(9,4 \mathrm{mg} \mathrm{dm}^{-3}\right)$. A profundidade em que foi encontrado um valor que não diferiu estatisticamente do arado e com significado agronômico similar foi a de $10-20 \mathrm{~cm}$ no plantio direto. As profundidades de $0-20$ e de $5-20 \mathrm{~cm}$ apresentaram valores similares aos da profundidade de $10-20 \mathrm{~cm}$, entretanto, têm significado agronômico diferente, já que se situam em faixas de disponibilidade diferentes de acordo com as recomendações da Comissão de Fertilidade do Solo de Goiás (1988) e da Comissão de Fertilidade do Solo do Estado de Minas Gerais (1989).

Murdock (1995) encontrou que a profundidade de amostragem no sistema plantio direto que apresentou valores de $\mathrm{P}$ e $\mathrm{K}$ correspondentes aos observados no sistema convencional $(0-18 \mathrm{~cm})$ foi de $0-10 \mathrm{~cm}$ e concluiu que esta profundidade poderia ser recomendada e que a adubação poderia ser a mesma nos dois sistemas de preparo do solo. Fiorin et al. (1998) também recomendaram a profundidade de amostragem de $0-10 \mathrm{~cm}$ para o sistema plantio direto já estabel ecido (após um período de quatro a cinco anos) como a profundidade adequada tanto para avaliar a necessi dade de calagem quanto para recomendar a adubação.

Tanto os resultados de Murdock (1995) como as recomendações de Fiorin et al . (1998) coinci dem com os deste trabalho, para $\mathrm{pH}, \mathrm{Ca}$, MgeK, mas diferem para oP. A profundidade deamostragem de $10-20 \mathrm{~cm}$ para o $\mathrm{P}$ no sistema plantio direto é lógica, já que é na camada superficial $(0-10 \mathrm{~cm})$ do solo que o el emento se concentra, em decorrência das repetidas adubações e de sua baixa mobilidade, como relatado por Muzilli (1983). Assim, nesta camada superficial, seria difícil encontrar valores para este elemento equival entes aos encontrados em uma camada de 0 $20 \mathrm{~cm}$, bastante revolvida pelo arado, como ocorre no sistema convencional.

Comparando os valores das características químicas avaliadas na profundidade de $0-15 \mathrm{~cm}$ no preparo do solo com grade com os obtidos na profundidade de 0-10 cm no plantio direto, verificouse que esses val ores mostraram-se equival entes, até para $\mathrm{P}$ (Quadro 1). A única diferença estatística ocorreu para Mg, embora os dois valores, 8,1 e $9,6 \mathrm{mmol}_{\mathrm{C}} \mathrm{dm}^{-3}$, respectivamente, para $0-15 \mathrm{~cm}$ na grade e $0-10 \mathrm{~cm}$ no plantio direto, situem-se na mesma faixa de disponibilidade no solo (CFSEMG, 1989). Em geral, a grade aradora mobiliza o solo apenas cerca de $10-15 \mathrm{~cm}$ de profundidade, originando similaridade de comportamento com o plantio direto. A recomendação de adubação poderia ser a mesma nos dois sistemas de preparo do sol o, já que as camadas estudadas apresentaram o mesmo índice de disponibilidadee a condição desimilaridade no rendimento da cultura, confirmando a condição proposta por Anghinoni \& Salet (1995).

\section{CONCLUSÕES}

1. A amostragem do solo na camada de $0-10 \mathrm{~cm}$ de profundidade no sistema plantio direto apresentou valores semel hantes aos do sistema convencional com arado para $\mathrm{pH}, \mathrm{Ca}, \mathrm{Mg}$ e K.

2. Para $P$, a profundidade de amostragem no plantio direto, que teve valor de disponibilidade semel hante ao do preparo convencional, foi de 10$20 \mathrm{~cm}$.

3. A amostragem do solo na camada de $0-10 \mathrm{~cm}$ de profundidade no sistema plantio direto apresentou val ores semel hantes aos do sistema com grade aradora para $\mathrm{pH}, \mathrm{Ca}, \mathrm{P}$ eK.

\section{LITERATURA CITADA}

ANGHINONI, I. \& SALET, R.L. Necessidades e metodologias de pesquisa para calibração de métodos de análise de solo e para determinação de necessidade de calagem no sistema plantio direto. In: SEMINÁRIO INTERNACIONAL DO SISTEMA PLANTIO DIRETO, 1., Passo Fundo, 1995. Resumos. Passo Fundo, EMBRAPA-CNPT, 1995. p.107110.

COMISSÃO DE FERTILIDADE DO SOLO DE GOIÁS - CFSGO. Recomendações de corretivos e fertilizantes para Goiás: 5 a aproximação. Goiânia, 1988. 101p. 
COMISSÃO DE FERTILIDADE DO SOLO DO ESTADO DE MINAS GERAIS - CFSEMG). Recomendações para o uso de corretivos e fertilizantes em Minas Gerais: 4a aproximação. Lavras, 1989. 176p.

EMPRESA BRASILEIRA DE PESQUISA AGROPECUÁRIA EMBRAPA. Centro Nacional de Pesquisa de Solos (Rio de J aneiro, RJ ). Manual de métodos de análise de solo. 2.ed.rev.atual. Rio de J aneiro, 1997. 212p. (EMBRAPACNPS. Documentos, 1)

FIORIN,J .E.; CANAL, I.N. \& CAMPOS, B.C. Fertilidade do Solo. In: CAMPOS, B.C. de, coord. A cultura do milho em plantio direto. CruzAIta, FUNDACEP/FECOTRIGO, 1998. p.1554.

MURDOCK, L. Soil sampling for no tillage: how different is it. Better Crops Plant Food, 69:21-23, 1995.

MUZI LLI, O. I nfluência do sistema de plantio direto, comparado ao convencional, sobre a fertilidade da camada arável do solo. R. Bras. Ci. Solo, 7:95-102, 1983.
OLIVEIRA, E.L.; PARRA, M.S. \& COSTA, A. Plantio convencional. In: IAPAR (Londrina, PR). Amostragem de solo para análise química: plantio direto e convencional, culturas perenes, várzeas, pastagens e capineiras. Londrina, 1996. p.9-10. (IAPAR - Circular, 90).

PREVEDELLO, B.M.S. Variabilidade espacial de parâmetros de sol o e planta. Piracicaba, Escola Superior deAgricultrua Luiz de Queiroz, 1987. 166p. (Tese de Doutorado)

SALET, R.L.; ANGHINONI, I.; KOCHHANN, R.A.; KRAY, C.H. $\&$ CONTE, E. Como fazer uma amostragem de solo no sistema plantio direto. In: SEMINÁRIO INTERNACIONAL DO SISTEMA PLANTIO DIRETO, 2., Passo Fundo, 1997. Anais. Passo Fundo, EMBRAPA-CNPT, 1997. p.205-207.

SOUZA, L.S. Variabilidade espacial do sol o em sistemas de manejo. Porto Alegre, Universidade Federal do Rio Grande do Sul, 1992. 162p. (Tese de Doutorado)

VIEIRA, M.J . Plantio direto. In: InstitutoAgronômico do Paraná. Amostragem de solo para análise química: plantio direto e convencional, culturas perenes, várzeas, pastagens e capineiras. Londrina, 1996. p.11-14. (IAPAR - Circular, 90) 